\title{
Okadaic Acid Time-Resolved Absorption and Resonance FT-IR and Raman Biospectroscopy and Density Functional Theory (DFT) Investigation of Vibronic-Mode Coupling Structure in Vibrational Spectra Analysis
}

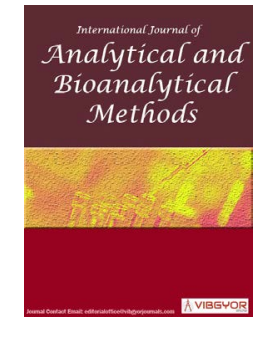

\section{Alireza Heidari ${ }^{12^{*}}$, Jennifer Esposito ${ }^{1}$ and Angela Caissutti ${ }^{1}$}

${ }^{1}$ Faculty of Chemistry, California South University, USA

${ }^{2}$ American International Standards Institute, USA

\begin{abstract}
Okadaic acid, $\mathrm{C}_{44} \mathrm{H}_{68} \mathrm{O}_{13}$, is a toxin produced by several species of dinoflagellates, and is known to accumulate in both marine sponges and shellfish. One of the primary causes of diarrhetic shellfish poisoning, Okadaic acid is a potent inhibitor of specific protein phosphatases and is known to have a variety of negative effects on cells. A polyketide, polyether derivative of a C38 fatty acid, Okadaic acid and other members of its family have shined light upon many biological processes both with respect to dinoflagellate polyketide synthesis as well as the role of protein phosphatases in cell growth. Parameters such as FT-IR and Raman vibrational wavelengths and intensities for single crystal Okadaic Acid are calculated using density functional theory and were compared with empirical results. The investigation about vibrational spectrum of cycle dimers in crystal with carboxyl groups from each molecule of acid was shown that it leads to create Hydrogen bonds for adjacent molecules. The current study aimed to investigate the possibility of simulating the empirical values. Analysis of vibrational spectrum of Okadaic Acid is performed based on theoretical simulation and FT-IR empirical spectrum and Raman empirical spectrum using density functional theory in levels of $\mathrm{HF} / 6-31 \mathrm{G}^{*}, \mathrm{HF} / 6-31++\mathrm{G}^{* *}, \mathrm{MP} 2 / 6-31 \mathrm{G}$, MP2/6-31++G**, BLYP/6-31G, BLYP/6-31++G** B3LYP/6-31G and B3LYP6-31-HEG ${ }^{* *}$. Vibration modes of methylene, carboxyl acid and phenyl cycle are separately investigated. The obtained values confirm high accuracy and validity of results obtained from calculations [1-42].
\end{abstract}

\section{Keywords}

Vibronic structure, Vibrational spectra analysis, Density Functional Theory (DFT), Okadaic acid, Non-Focal functions of becke, Correlation functions of Lee-Yang-Parr, Time-Resolved absorption and resonance, FT-IR and Raman biospectroscopy

\section{Introduction}

Okadaic acid, $\mathrm{C}_{44} \mathrm{H}_{68} \mathrm{O}_{13}$, is a toxin produced by several species of dinoflagellates, and is known to accumulate in both marine sponges and shellfish. One of the primary causes of diarrhetic shellfish poi- soning, Okadaic acid is a potent inhibitor of specific protein phosphatases and is known to have a variety of negative effects on cells. A polyketide, polyether derivative of a C38 fatty acid, Okadaic acid and other members of its family have shined light

*Corresponding author: Alireza Heidari, Faculty of Chemistry, California South University, 14731 Comet St. Irvine, CA 92604; American International Standards Institute, Irvine, CA 3800, USA

Accepted: May 16, 2019; Published: May 18, 2019

Copyright: @ 2019 Heidari A, et al. This is an open-access article distributed under the terms of the Creative Commons Attribution License, which permits unrestricted use, distribution, and reproduction in any medium, provided the original author and source are credited.

Heidari et al. Int J Analyt Bioanalyt Methods 2019, 1:004 
upon many biological processes both with respect to dinoflagellate polyketide synthesis as well as the role of protein phosphatases in cell growth. Density Functional Theory (DFT) is one of the most powerful calculation methods for electronic structures [5-7]. Numerous results have been previously studied and indicate successful use of these methods [8-10]. The theory is one of the most appropriate methods for simulating the vibrational wavenumbers, molecular structure as well as total energy. It may be useful to initially consider the calculated results by density functional theory using $\mathrm{HF} / 6$ $31 \mathrm{G}^{*}, \mathrm{HF} / 6-31++\mathrm{G}^{* *}, \mathrm{MP} 2 / 6-31 \mathrm{G}, \mathrm{MP} 2 / 6-31++\mathrm{G}^{* *}$, $\mathrm{BLYP} / 6-31 \mathrm{G}, \mathrm{BLYP} / 6-31++\mathrm{G}^{* *}, \mathrm{~B} 3 \mathrm{LYP} / 6-31 \mathrm{G}$ and B3LYP6-31-HEG ${ }^{* *}$ approach [11-16]. It should be noted that calculations are performed by considering one degree of quantum interference as well as polarization effects of $2 d$ orbitals in interaction [17-47].

Okadaic acid is a tropical weed belonging to Toxins family. Amongst Toxins, Okadaic acid contains anti-fungal activity, acetylcholinesterase inhibitory activity, anti-oxidant activity [48-64], mast cell stabilization and membrane protection activity [6592], anti-bacterial activity [93-127] and anti-cancer activity [128-145], anti-hyperglycemic an anti-hyperlipidemic effects [146-156] and anti-arthritic activity, immunomodulatory activity [157-173] and anti-diabetic activity [174-187]. Our earlier report stated that the Okadaic acid has high anti-oxidant activity [188-200]. The observations show that Okadaic acid can be used for pharmaceutical applications. In this view, Okadaic acid was taken and examined for its phytochemical and active principles in vitro anti-oxidant models and in silico approach for anti-histamine activity. Free radicals are atoms with unpaired electrons which can cause various diseases. Intake of vitamin $\mathrm{E}$ can reduce the problems associated with free radicals in the body [201-209]. The unpaired electrons of free-radical accumulation cause oxidative stress in the body. Oxidative stress causes cell damage leading to various health issues such as chronic disease, cancer, autoimmune disorders, aging, cataract, rheumatoid arthritis, cardiovascular diseases, neurodegenerative diseases, respiratory disorders [210-218] and also the induced oxidative stress causes bronchial contraction by the release of cyclooxygenase and lipoxygenase in the airway that leads to bronchial asthma in human [219-225]. Asthma is a chronic inflammatory lung disease that happens due to the respiratory infection triggered by the inhalation of allergens like tobacco smoke, air pollutants, genetic and environment factors [226-232] which leads to the release of histamine and leukotrienes from the mast cell in the lung. The high release of histamine due to allergic reactions is regulated by histamine $\mathrm{H} 1$ receptor [233-235]. Histamine affects the immune response and related functions in human through $\mathrm{H} 1, \mathrm{H} 2, \mathrm{H} 3$ and $\mathrm{H} 4$ receptors activation with their intracellular signals [236-238]. The present research work demonstrates the chemotaxonomy of such valuable plant, from the genus of Okadaic acid. In addition, pharmaceutical applications

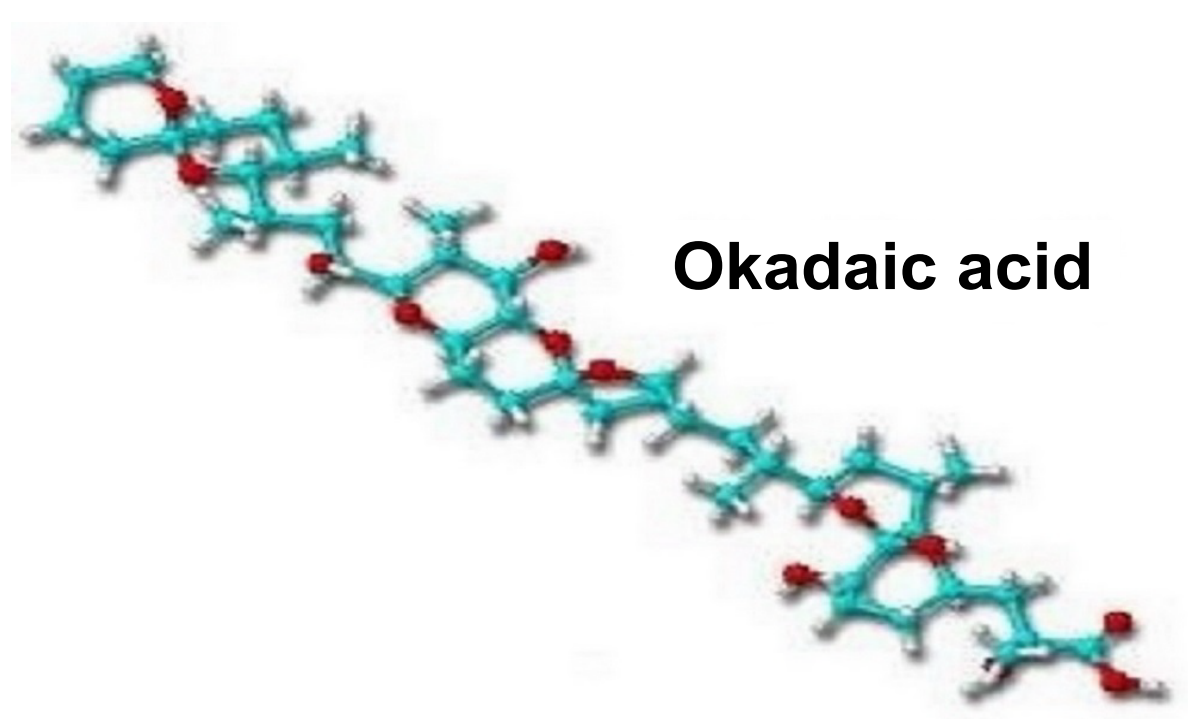

Figure 1: Section of the okadaic acid [43-93]. 
such as in vitro anti-oxidant and in silico anti-histamine activity of their active principles as natural remedy was examined.

\section{Details of Calculations}

All calculations of molecular orbital in the base of ab are performed by Gaussian 09. In calculation process, the structure of Okadaic Acid molecule (Figure 1 ) is optimized and FT-IR and Raman wavenumbers are calculated using $\mathrm{HF} / 6-31 \mathrm{G}^{*}, \mathrm{HF} / 6$ $31++G^{* *}, M P 2 / 6-31 G, M P 2 / 6-31++G^{* *}, B L Y P / 6-31 G$, BLYP/6-31++G ${ }^{* *}$, B3LYP/6-31G and B3LYP6-31$\mathrm{HEG}^{* *}$ base. All optimized structures are adjusted with minimum energy. Harmonic vibrational wavenumbers are calculated using second degree of derivation to adjust convergence on potential surface as good as possible and to evaluate vibrational energies at zero point. In optimized structures considered in the current study, virtual frequency modes are not observed which indicates that the minimum potential energy surface is correctly chosen. The optimized geometry is calculated by minimizing the energy relative to all geometrical quantities without forcing any constraint on molecular symmetry. Calculations were performed by Gaussian 09. The current calculation is aimed to maximize structural optimization using density functional theory. The calculations of density functional theory is performed by $\mathrm{HF} / 6-31 \mathrm{G}^{*}, \mathrm{HF} / 6-31++\mathrm{G}^{* *}$, MP2/6-31G, MP2/6-31++G** ${ }^{* *}$ BLYP/6-31G, BLY$\mathrm{P} / 6-31++\mathrm{G}^{* *}$, B3LYP/6-31G and B3LYP6-31-HEG ${ }^{* *}$ function in which non-focal functions of Becke and correlation functions of Lee-Yang-Parr beyond the Franck-Condon approximation are used. After completion of optimization process, the second order derivation of energy is calculated as a function of core coordination and is investigated to evaluate whether the structure is accurately minimized. Vibrational frequencies used to simulate spectrums presented in the current study are derived from these second order derivatives. All calculations are performed for room temperature of $414(\mathrm{~K})$.

\section{Vibration Analysis}

Analysis of vibrational spectrum of Okadaic Acid is performed based on theoretical simulation and FT-IR empirical spectrum and Raman empirical spectrum using density functional theory in levels of HF/6-31G* $\mathrm{HF} / 6-31++\mathrm{G}^{* *}, \mathrm{MP} 2 / 6-31 \mathrm{G}, \mathrm{MP} 2 / 6$ $31++G^{* *}$, BLYP/6-31G, BLYP/6-31++G** $B 3 L Y P / 6-$ $31 \mathrm{G}$ and B3LYP6-31-HEG** Vibration modes of methylene, carboxyl acid and phenyl cycle are separately investigated.

$\mathrm{C}-\mathrm{H}$ stretching vibrations in single replacement of benzene cycles are usually seen in band range of $3225-3475 \mathrm{~cm}^{-1}$. Weak Raman bands are at $3214 \mathrm{~cm}^{-1}$ and $3227 \mathrm{~cm}^{-1}$. C-C stretching mode is a strong Raman mode at $1199 \mathrm{~cm}^{-1}$. Raman weak band is seen at 1673 $\mathrm{cm}^{-1}$, too. Bending mode of $\mathrm{C}-\mathrm{H}$ is emerged as a weak mode at $1423 \mathrm{~cm}^{-1}$ and $1222 \mathrm{~cm}^{-1}$ and a strong band at $1306 \mathrm{~cm}^{-1}$ in Raman spectrum. Raman is considerably active in the range of $1225-1475 \mathrm{~cm}^{-1}$ which $1218 \mathrm{~cm}^{-1}$ indicates this issue.

C-H skew-symmetric stretching mode of methylene group is expected at $3210 \mathrm{~cm}^{-1}$ and its symmetric mode is expected at $3024 \mathrm{~cm}^{-1}$. Skew-symmetric stretching mode of $\mathrm{CH}_{2}$ in Okadaic Acid has a mode in mid-range of Raman spectrum at 3125-3245 $\mathrm{cm}^{-1}$. When this mode is symmetric, it is at 3120 $\mathrm{cm}^{-1}$ and is sharp. The calculated wavenumbers of higher modes are at $3088 \mathrm{~cm}^{-1}$ and $3118 \mathrm{~cm}^{-1}$ for symmetric and skew-symmetric stretching mode of methylene, respectively.

Scissoring vibrations of $\mathrm{CH}_{2}$ are usually seen at the range of $1555-1606 \mathrm{~cm}^{-1}$ which often includes mid-range bands. Weak bands at $1565 \mathrm{~cm}^{-1}$ are scissoring modes of $\mathrm{CH}_{2}$ in Raman spectrum. Moving vibrations of methylene are usually seen at 1494 $\mathrm{cm}^{-1}$. For the investigated chemical in the current study, these vibrations are at $1364 \mathrm{~cm}^{-1}$ were calculated using density functional theory. Twisting and rocking vibrations of $\mathrm{CH}_{2}$ are seen in Raman spectrum at $940 \mathrm{~cm}^{-1}$ and $1214 \mathrm{~cm}^{-1}$, respectively, which are in good accordance with the results at $924 \mathrm{~cm}^{-1}$ and $1189 \mathrm{~cm}^{-1}$, respectively.

In a non-ionized carboxyl group $(\mathrm{COOH})$, stretching vibrations of carbonyl $[\mathrm{C}=\mathrm{O}]$ are mainly observed at the range of $1865-1913 \mathrm{~cm}^{-1}$. If dimer is considered as an intact constituent, two stretching vibrations of carbonyl for symmetric stretching are at $1765-1810 \mathrm{~cm}^{-1}$ in Raman spectrum. In the current paper, stretching vibration of carbonyl mode is at $1822 \mathrm{~cm}^{-1}$ which is a mid-range value.

Stretching and bending bands of hydroxyl can be identified by width and band intensity which in turn is dependent on bond length of Hydrogen. In dimer form of Hydrogen bond, stretching band of $\mathrm{O}-\mathrm{H}$ is of a strong Raman peak at $1392 \mathrm{~cm}^{-1}$ which is due to in-plain metamorphosis mode. Out-of-plain mode of O-H group is a very strong mode of peak at 1074 

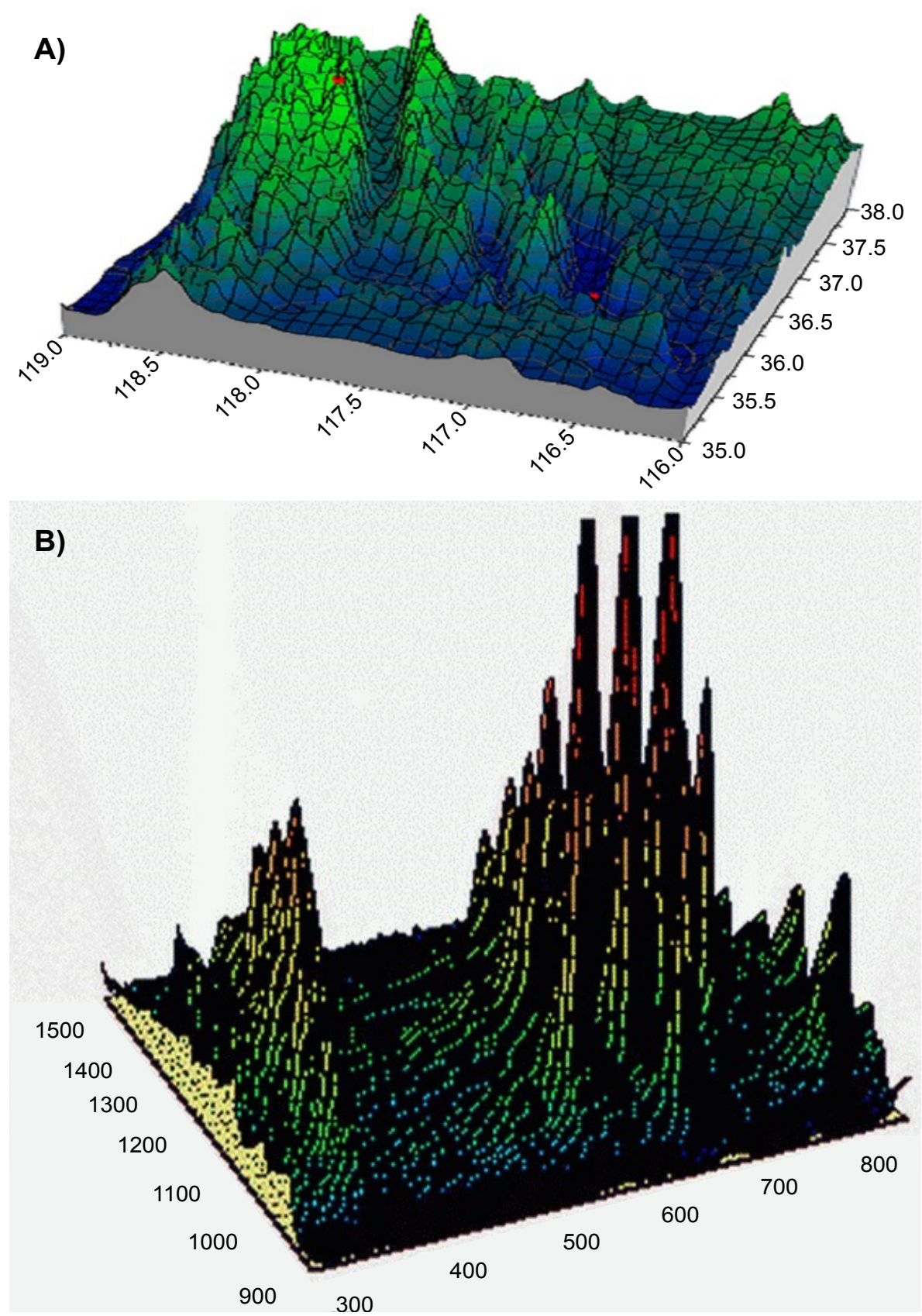

Figure 2: 3D Simulation of a) FT-IR spectrum and b) Raman spectrum of Okadaic Acid. It should be noted that in the Figure a $x$-axis shows wavenumbers $\left(\mathrm{cm}^{-1}\right), y$-axis shows percent transmission (T\%) and z-axis shows time(s). Also, in the Figure $b \mathrm{x}$-axis shows Raman shifts $\left(\mathrm{cm}^{-1}\right), y$-axis shows intensity and z-axis shows time(s).

$\mathrm{cm}^{-1}$ of Raman spectrum. The stretching mode of $\mathrm{C}-\mathrm{O}(\mathrm{H})$ emerges as a mid-band of Raman spectrum at $1272 \mathrm{~cm}^{-1}$.

Lattice vibrations are usually seen at the range of $0-575 \mathrm{~cm}^{-1}$. These modes are induced by rotary and transferring vibrations of molecules and vibrations and are including Hydrogen bond. Bands with low wavenumbers of Hydrogen bond vibrations in FT-IR and Raman spectrum (Figure 2) are frequently weak, width and unsymmetrical. Rotary lattice vibrations are frequently stronger than transferring ones. Intra-molecular vibrations with low wavenumbers involving two-bands $\mathrm{O}-\mathrm{H}$...O dimer at $113 \mathrm{~cm}^{-1}, 218$ $\mathrm{cm}^{-1}$ and $274 \mathrm{~cm}^{-1}$ are attributed to a rotary moving of two molecules involving in-plain rotation of molecules against each other.

\section{Conclusion and Summary}

Calculations of density functional theory using $\mathrm{HF} / 6-31 \mathrm{G}^{*}, \mathrm{HF} / 6-31++\mathrm{G}^{* *}, \mathrm{MP} 2 / 6-31 \mathrm{G}, \mathrm{MP} 2 / 6-$ 
31++G ${ }^{* *}, B L Y P / 6-31 G, B L Y P / 6-31++G^{* *}, B 3 L Y P / 6-$ $31 \mathrm{G}$ and B3LYP6-31-HEG ${ }^{* *}$ levels were used to obtain vibrational wavenumbers and intensities in single crystal of Okadaic Acid. Investigation and consideration of vibrational spectrum confirm the formation of dimer cycles in the investigated crystal with carboxyl groups from each Hydrogen molecule of acid protected from adjacent molecules. The calculated vibrational spectrum which obtains from calculations of density functional theory is in good accordance with recorded empirical values which indicates successful simulation of the problem. The obtained results indicate that the results obtained from theoretical calculations are valid through comparing with empirical recorded results.

\section{Acknowledgements}

Authors are supported by an American International Standards Institute (AISI) Future Fellowship Grant FT1201009373517. We acknowledge Ms. Isabelle Villena for instrumental support and $\mathrm{Dr}$. Michael N. Cocchi for constructing graphical abstract figure. We gratefully acknowledge Prof. Dr. Christopher Brown for proofreading the manuscript.

\section{References}

1. A Heidari, C Brown (2015) Study of composition and morphology of cadmium oxide (cdo) nanoparticles for eliminating cancer cells. J Nanomed Res 2: 20.

2. A Heidari, C Brown (2015) Study of surface morphological, phytochemical and structural characteristics of Rhodium (III) Oxide $\left(\mathrm{Rh}_{2} \mathrm{O}_{3}\right)$ nanoparticles. International Journal of Pharmacology, Phytochemistry and Ethnomedicine 1: 15-19.

3. A Heidari (2016) An experimental biospectroscopic study on seminal plasma in determination of semen quality for evaluation of male infertility. Int J Adv Technol 7: e007.

4. A Heidari (2016) Extraction and preconcentration of $\mathrm{N}$-Tolyl-Sulfonyl-Phosphoramid-Saeure-Dichlorid as an anti-cancer drug from plants: A pharmacognosy study. J Pharmacogn Nat Prod 2: e103.

5. A Heidari (2016) A thermodynamic study on hydration and dehydration of DNA and RNAamphiphile complexes. J Bioeng Biomed Sci S: 006.

6. A Heidari (2016) Computational studies on molecular structures and carbonyl and ketene groups effects of singlet and triplet energies of Azidoketene $\mathrm{O}=\mathrm{C}=\mathrm{CH}$ $\mathrm{NNN}$ and Isocyanatoketene $\mathrm{O}=\mathrm{C}=\mathrm{CH}-\mathrm{N}=\mathrm{C}=\mathrm{O}$. J Appl Computat Math 5: e142.
7. A Heidari (2016) Study of irradiations to enhance the induces the dissociation of hydrogen bonds between peptide chains and transition from helix structure to random coil structure using ATR-FTIR, Raman and ${ }^{1}$ HNMR spectroscopies. J Biomol Res Ther 5: e146.

8. A Heidari (2016) Future prospects of point fluorescence spectroscopy, fluorescence imaging and fluorescence endoscopy in photodynamic therapy (PDT) for cancer cells. J Bioanal Biomed 8: e135.

9. A Heidari (2016) A bio-spectroscopic study of DNA density and color role as determining factor for absorbed irradiation in cancer cells. Adv Cancer Prev 1: e102.

10.A Heidari (2016) Manufacturing process of solar cells using cadmium oxide (CdO) and rhodium (III) oxide $\left(\mathrm{Rh}_{2} \mathrm{O}_{3}\right)$ nanoparticles. J Biotechnol Biomater 6: e125.

11.A Heidari (2016) A novel experimental and computational approach to photobiosimulation of telomeric DNA/RNA: A biospectroscopic and photobiological study. J Res Development 4: 144.

12.A Heidari (2016) Biochemical and pharmacodynamical study of microporous molecularly imprinted polymer selective for vancomycin, teicoplanin, oritavancin, telavancin and dalbavancin binding. Biochem Physiol 5: e146.

13.A Heidari (2016) Anti-cancer effect of UV irradiation at presence of cadmium oxide ( $\mathrm{CdO}$ ) nanoparticles on dna of cancer cells: A photodynamic therapy study. Arch Cancer Res 4: 1.

14.A Heidari (2016) Biospectroscopic study on multicomponent reactions (MCRs) in two a-type and b-type conformations of nucleic acids to determine ligand binding modes, binding constant and stability of nucleic acids in cadmium oxide ( $\mathrm{CdO}$ ) nanoparticles-nucleic acids complexes as anti-cancer drugs. Arch Cancer Res 4: 2.

15.A Heidari (2016) Simulation of temperature distribution of DNA/RNA of human cancer cells using time-dependent bio-heat equation and $\mathrm{Nd}$ : YAG lasers. Arch Cancer Res 4: 2.

16.A Heidari (2016) Quantitative structure-activity relationship (QSAR) approximation for Cadmium Oxide (CdO) and Rhodium (III) Oxide $\left(\mathrm{Rh}_{2} \mathrm{O}_{3}\right)$ nanoparticles as anti-cancer drugs for the catalytic formation of proviral DNA from viral RNA using multiple linear and non-linear correlation approach. Ann Clin Lab Res 4: 1.

17.A Heidari (2016) Biomedical study of cancer cells DNA therapy using laser irradiations at presence of 
intelligent nanoparticles. J Biomedical Sci 5: 2.

18. A Heidari (2016) Measurement the amount of vitamin D2 (ergocalciferol), vitamin D3 (cholecalciferol) and absorbable calcium $\left(\mathrm{Ca}^{2+}\right)$, iron (II) $\left(\mathrm{Fe}^{2+}\right)$, magnesium $\left(\mathrm{Mg}^{2+}\right)$, phosphate $\left(\mathrm{PO}^{4-}\right)$ and zinc $\left(\mathrm{Zn}^{2+}\right)$ in apricot using high-performance liquid chromatography (HPLC) and spectroscopic techniques. J Biom Biostat 7: 292.

19.A Heidari (2016) Spectroscopy and quantum mechanics of the helium dimer $\left(\mathrm{He}^{2+}\right)$, neon dimer $\left(\mathrm{Ne}^{2+}\right)$, argon dimer $\left(\mathrm{Ar}^{2+}\right)$, krypton dimer $\left(\mathrm{Kr}^{2+}\right)$, xenon dimer $\left(\mathrm{Xe}^{2+}\right)$, radon dimer $\left(\mathrm{Rn}^{2+}\right)$ and ununoctium dimer $\left(\mathrm{Uuo}^{2+}\right)$ molecular cations. Chem Sci J 7: e112.

20.A Heidari (2016) Human toxicity photodynamic therapy studies on DNA/RNA complexes as a promising new sensitizer for the treatment of malignant tumors using bio-spectroscopic techniques. J Drug Metab Toxicol 7: e129.

21.A Heidari (2016) Novel and stable modifications of intelligent cadmium oxide ( $\mathrm{CdO}$ ) nanoparticles as anti-cancer drug in formation of nucleic acids complexes for human cancer cells treatment. Biochem Pharmacol (Los Angel) 5: 207.

22.A Heidari (2016) A combined computational and $\mathrm{QM} / \mathrm{MM}$ molecular dynamics study on boron nitride nanotubes (BNNTs), amorphous boron nitride nanotubes (a-BNNTs) and hexagonal boron nitride nanotubes (h-BNNTs) as hydrogen storage. Struct Chem Crystallogr Commun 2: 1.

23.A Heidari (2016) Pharmaceutical and analytical chemistry study of cadmium oxide (CdO) nanoparticles synthesis methods and properties as anti-cancer drug and its effect on human cancer cells. Pharm Anal Chem Open Access 2: 113.

24.A Heidari (2016) A chemotherapeutic and biospectroscopic investigation of the interaction of double-standard DNA/RNA-binding molecules with cadmium oxide (CdO) and rhodium (III) oxide $\left(\mathrm{Rh}_{2} \mathrm{O}_{3}\right)$ nanoparticles as anti-cancer drugs for cancer cells' treatment. Chemo Open Access 5: e129.

25.A Heidari (2016) Pharmacokinetics and experimental therapeutic study of DNA and other biomolecules using lasers: Advantages and applications. J Pharmacokinet Exp Ther 1: e005.

26.A Heidari (2016) Determination of ratio and stability constant of DNA/RNA in human cancer cells and cadmium oxide (cdo) nanoparticles complexes using analytical electrochemical and spectroscopic techniques. Insights Anal Electrochem 2: 1.

27.A Heidari (2016) Discriminate between antibacterial and non-antibacterial drugs artificial neutral networks of a multilayer perceptron (MLP) type using a set of topological descriptors. J Heavy Met Toxicity Dis 1: 2.

28.A Heidari (2016) Combined theoretical and computational study of the belousov-zhabotinsky chaotic reaction and curtius rearrangement for synthesis of mechlorethamine, cisplatin, streptozotocin, cyclophosphamide, melphalan, busulphan and bcnu as anti-cancer drugs. Insights Med Phys 1: 2.

29.A Heidari (2016) A translational biomedical approach to structural arrangement of amino acids' complexes: A combined theoretical and computational study. Transl Biomed 7: 2.

30.A Heidari (2016) Ab Initio and density functional theory (DFT) studies of dynamic nmr shielding tensors and vibrational frequencies of DNA/RNA and cadmium oxide ( $\mathrm{CdO}$ ) nanoparticles complexes in human cancer cells. J Nanomedine Biotherapeutic Discov 6: e144.

31.A Heidari (2016) Molecular dynamics and montecarlo simulations for replacement sugars in insulin resistance, obesity, LDL cholesterol, triglycerides, metabolic syndrome, type 2 diabetes and cardiovascular disease: A glycobiological study. J Glycobiol 5: e111.

32.A Heidari (2016) Synthesis and study of 5-[(Phenylsulfonyl)Amino]-1,3,4-Thiadiazole-2Sulfonamide as potential anti-pertussis drug using chromatography and spectroscopy techniques. Transl Med (Sunnyvale) 6: e138.

33.A Heidari (2016) Nitrogen, oxygen, phosphorus and sulphur heterocyclic anti-cancer nano drugs separation in the supercritical fluid of ozone $\left(\mathrm{O}_{3}\right)$ using soave-redlich-kwong (SRK) and pang-robinson (PR) equations. Electronic J Biol 12: 4.

34.A Heidari (2016) An analytical and computational infrared spectroscopic review of vibrational modes in nucleic acids. Austin J Anal Pharm Chem 3: 1058.

35.A Heidari, C Brown (2016) Phase, composition and morphology study and analysis of Os-Pd/HfC nanocomposites. Nano Res Appl 2: 1.

36.A Heidari, C Brown (2016) Vibrational spectroscopic study of intensities and shifts of symmetric vibration modes of ozone diluted by cumene. International Journal of Advanced Chemistry 4: 5-9.

37.A Heidari (2016) Study of the role of anti-cancer molecules with different sizes for decreasing corresponding bulk tumor multiple organs or tissues. 
Arch Can Res 4: 2.

38.A Heidari (2016) Genomics and proteomics studies of zolpidem, necopidem, alpidem, saripidem, miroprofen, zolimidine, olprinone and abafungin as anti-tumor, peptide antibiotics, antiviral and central nervous system (CNS) drugs. J Data Mining Genomics \& Proteomics 7: e125.

39.A Heidari (2016) Pharmacogenomics and pharmacoproteomics studies of phosphodiesterase- 5 (PDE5) inhibitors and paclitaxel albumin-stabilized nanoparticles as sandwiched anti-cancer nano drugs between two dna/rna molecules of human cancer cells. J Pharmacogenomics Pharmacoproteomics 7: e153.

40.A Heidari (2016) Biotranslational medical and biospectroscopic studies of cadmium oxide (CdO) Nanoparticles-DNA/RNA straight and cycle chain complexes as potent anti-viral, anti-tumor and antimicrobial drugs: A clinical approach. Transl Biomed 7: 2.

41.A Heidari (2016) A comparative study on simultaneous determination and separation of adsorbed cadmium oxide (CdO) nanoparticles on DNA/RNA of human cancer cells using biospectroscopic techniques and dielectrophoresis (DEP) method. Arch Can Res 4: 2.

42.A Heidari (2016) Cheminformatics and system chemistryof cisplatin, carboplatin, nedaplatin, oxaliplatin, heptaplatin and lobaplatin as anticancer nano drugs: A combined computational and experimental study. J Inform Data Min 1: 3.

43.A Heidari (2016) Linear and non-linear quantitative structure-anti-cancer-activity relationship (QSACAR) study of hydrous ruthenium (IV) oxide $\left(\mathrm{RuO}_{2}\right)$ nanoparticles as non-nucleoside reverse transcriptase inhibitors (NNRTIs) and anti-cancer nano drugs. J Integr Oncol 5: e110.

44.A Heidari (2016) Synthesis, characterization and biospectroscopic studies of cadmium oxide (CdO) nanoparticles-nucleic acids complexes absence of soluble polymer as a protective agent using nucleic acids condensation and solution reduction method. J Nanosci Curr Res 1: e101.

45.A Heidari (2016) Coplanarity and collinearity of 4'-Dinonyl-2,2'-Bithiazole in one domain of bleomycin and pingyangmycin to be responsible for binding of cadmium oxide ( $\mathrm{CdO}$ ) nanoparticles to DNA/RNA bidentate ligands as anti-tumor nano drug. Int J Drug Dev \& Res 8: 007-008.

46.A Heidari (2016) A pharmacovigilance study on linear and non-linear quantitative structure (chromatographic) retention relationships (QSRR) models for the prediction of retention time of anticancer nano drugs under synchrotron radiations. J Pharmacovigil 4: e161.

47.A Heidari (2016) Nanotechnology in preparation of semipermeable polymers. J Adv Chem Eng 6: 157.

48. A Heidari (2016) A gastrointestinal study on linear and non-linear quantitative structure (chromatographic) retention relationships (QSRR) models for analysis 5 -aminosalicylates nano particles as digestive system nano drugs under synchrotron radiations. J Gastrointest Dig Syst 6: e119.

49.A Heidari (2016) DNA/RNA fragmentation and cytolysis in human cancer cells treated with diphthamide nano particles derivatives. Biomedical Data Mining 5: e102.

50.A Heidari (2016) A successful strategy for the prediction of solubility in the construction of quantitative structure-activity relationship (QSAR) and quantitative structure-property relationship (qspr) under synchrotron radiations using genetic function approximation (gfa) algorithm. J Mol Biol Biotechnol 1: 1.

51.A Heidari (2016) Computational study on molecular structures of $\mathrm{C}_{20}, \mathrm{C}_{60}, \mathrm{C}_{240}, \mathrm{C}_{540}, \mathrm{C}_{960}, \mathrm{C}_{2160}$ and $\mathrm{C}_{3840}$ fullerene nano molecules under synchrotron radiations using fuzzy logic. J Material Sci Eng 5: 282.

52.A Heidari (2016) Graph theoretical analysis of zigzag polyhexamethylene biguanide, polyhexamethylene adipamide, polyhexamethylene biguanide gauze and polyhexamethylene biguanide hydrochloride (PHMB) boron nitride nanotubes (BNNTs), amorphous boron nitride nanotubes (a-BNNTs) and hexagonal boron nitride nanotubes (h-BNNTs). J Appl Computat Math 5: e143.

53.A Heidari (2016) The impact of high resolution imaging on diagnosis. Int $\mathrm{J}$ Clin Med Imaging 3: $1000 \mathrm{e} 101$.

54.A Heidari (2016) A comparative study of conformational behavior of isotretinoin (13-Cis Retinoic Acid) and tretinoin (All-Trans Retinoic Acid (ATRA)) nano particles as anti-cancer nano drugs under synchrotron radiations using hartree-fock (HF) and density functional theory (DFT) methods. Insights in Biomed 1: 2.

55.A Heidari (2016) Advances in logic, operations and computational mathematics. J Appl Computat Math 5: 5.

56.A Heidari (2016) Mathematical equations in predicting physical behavior. J Appl Computat Math 


\section{5: 5 .}

57.A Heidari (2016) Chemotherapy a last resort for cancer treatment. Chemo Open Access 5: 4.

58. A Heidari (2016) Separation and pre-concentration of metal cations-dna/rna chelates using molecular beam mass spectrometry with tunable vacuum ultraviolet (VUV) synchrotron radiation and various analytical methods. Mass Spectrom Purif Tech 2: e101.

59.A Heidari (2016) Yoctosecond quantitative structureactivity relationship (QSAR) and quantitative structure-property relationship (QSPR) under synchrotron radiations studies for prediction of solubility of anti-cancer nano drugs in aqueous solutions using genetic function approximation (GFA) algorithm. Insight Pharm Res 1: 1.

60.A Heidari (2016) Cancer risk prediction and assessment in human cells under synchrotron radiations using quantitative structure activity relationship (QSAR) and quantitative structure properties relationship (QSPR) studies. Int J Clin Med Imaging 3: 516.

61.A Heidari (2016) A novel approach to biology. Electronic J Biol 12: 4.

62.A Heidari (2016) Innovative biomedical equipment's for diagnosis and treatment. J Bioengineer \& Biomedical Sci 6: 2.

63.A Heidari (2016) Integrating precision cancer medicine into healthcare, medicare reimbursement changes and the practice of oncology: Trends in oncology medicine and practices. J Oncol Med \& Pract 1: 2.

64.A Heidari (2016) Promoting convergence in biomedical and biomaterials sciences and silk proteins for biomedical and biomaterials applications: An introduction to materials in medicine and bioengineering perspectives. J Bioengineer \& Biomedical Sci 6: 3.

65.A Heidari (2017) X-Ray fluorescence and X-Ray diffraction analysis on discrete element modeling of nano powder metallurgy processes in optimal container design. J Powder Metall Min 6: 1.

66. A Heidari (2017) Biomolecular spectroscopy and dynamics of nano-sized molecules and clusters as cross-linking-induced anti-cancer and immuneoncology nano drugs delivery in DNA/RNA of human cancer cells' membranes under synchrotron radiations: A payload-based perspective. Arch Chem Res 1: 2 .

67.A Heidari (2017) Deficiencies in repair of double- standard dna/rna-binding molecules identified in many types of solid and liquid tumors oncology in human body for advancing cancer immunotherapy using computer simulations and data analysis: Number of mutations in a synchronous tumor varies by age and type of synchronous cancer. J Appl Bioinforma Comput Biol 6: 1.

68.A Heidari (2017) Electronic coupling among the five nanomolecules shuts down quantum tunneling in the presence and absence of an applied magnetic field for indication of the dimer or other provide different influences on the magnetic behavior of single molecular magnets (SMMs) as qubits for quantum computing. Glob J Res Rev 4: 2.

69.A Heidari (2017) Polymorphism in nano-sized graphene ligand-induced transformation of $\mathrm{Au}_{38}-$ $\mathrm{xAg}_{\mathrm{x}} / \mathrm{xCu_{x }}(\mathrm{SPh}-\mathrm{tBu})_{24}$ to $\mathrm{Au}_{36}-\mathrm{xAg}_{\mathrm{x}} / \mathrm{xCu}_{\mathrm{x}}(\mathrm{SPh}-\mathrm{tBu})_{24}$ ( $\mathrm{x}$ $=1-12$ ) nanomolecules for synthesis of $A u_{144}-x A g_{x} /$ $x \mathrm{Cu}_{\mathrm{x}}\left[(\mathrm{SR})_{60},\left(\mathrm{SC}_{4}\right)_{60},\left(\mathrm{SC}_{6}\right)_{60},\left(\mathrm{SC}_{12}\right)_{60},(\mathrm{PET})_{60},(\mathrm{p}-\mathrm{MBA})_{60}\right.$ $(\mathrm{F})_{60},(\mathrm{Cl})_{60},(\mathrm{Br})_{60},(\mathrm{I})_{60},(\mathrm{At})_{60},(\text { Uus })_{60}$ and $\left.\left(\mathrm{SC}_{6} \mathrm{H}_{13}\right)_{60}\right]$ nano clusters as anti-cancer nano drugs. J Nanomater Mol Nanotechnol 6: 3.

70.A Heidari (2017) Biomedical resource oncology and data mining to enable resource discovery in medical, medicinal, clinical, pharmaceutical, chemical and translational research and their applications in cancer research. Int J Biomed Data Min 6: e103.

71.A Heidari (2017) Study of synthesis, pharmacokinetics, pharmacodynamics, dosing, stability, safety and efficacy of olympiadane nanomolecules as agent for cancer enzymotherapy, immunotherapy, chemotherapy, radiotherapy, hormone therapy and targeted therapy under synchrotorn radiation. J Dev Drugs 6: e154.

72. A Heidari (2017) A novel approach to future horizon of top seven biomedical research topics to watch in 2017: Alzheimer's, ebola, hypersomnia, human immunodeficiency virus (HIV), tuberculosis (TB), microbiome/antibiotic resistance and endovascular stroke. J Bioengineer \& Biomedical Sci 7: e127.

73.A Heidari (2017) Opinion on computational fluid dynamics (cfd) technique. Fluid Mech Open Acc 4: 157.

74.A Heidari (2017) Concurrent diagnosis of oncology influence outcomes in emergency general surgery for colorectal cancer and multiple sclerosis (MS) treatment using magnetic resonance imaging (MRI) and $A u_{329}(S R)_{84}, A_{329-x} A_{g_{x}}(S R)_{84}, A u_{144}(S R)_{60}, A_{68}(S R)_{36}$, $\mathrm{Au}_{30}(\mathrm{SR})_{18}, \mathrm{Au}_{102}(\mathrm{SPh})_{44}, \mathrm{Au}_{38}(\mathrm{SPh})_{24}, \mathrm{Au}_{38}\left(\mathrm{SC}_{2} \mathrm{H}_{4} \mathrm{Ph}\right)_{24}$, $\mathrm{Au}_{21} \mathrm{~S}(\mathrm{SAdm})_{15}, \mathrm{Au}_{36}(\mathrm{pMBA})_{24}$ and $\mathrm{Au}_{25}(\mathrm{pMBA})_{18}$ nano 
clusters. J Surgery Emerg Med 1: 21.

75.A Heidari (2017) Developmental cell biology in adult stem cells death and autophagy to trigger a preventive allergic reaction to common airborne allergens under synchrotron radiation using nanotechnology for therapeutic goals in particular allergy shots (immunotherapy). Cell Biol (Henderson, NV) 6: 1.

76. A Heidari (2017) Changing metal powder characteristics for elimination of the heavy metals toxicity and diseases in disruption of extracellular matrix (ECM) proteins adjustment in cancer metastases induced by osteosarcoma, chondrosarcoma, carcinoid, carcinoma, ewing's sarcoma, fibrosarcoma and secondary hematopoietic solid or soft tissue tumors. J Powder Metall Min 6: 170.

77.A Heidari (2017) Nanomedicine-based combination anti-cancer therapy between nucleic acids and anticancer nano drugs in covalent nano drugs delivery systems for selective imaging and treatment of human brain tumors using hyaluronic acid, alguronic acid and sodium hyaluronate as anti-cancer nano drugs and nucleic acids delivery under synchrotron radiation. Am J Drug Deliv 5: 2.

78.A Heidari (2017) Clinical trials of dendritic cell therapies for cancer exposing vulnerabilities in human cancer cells' metabolism and metabolomics: New discoveries, unique features inform new therapeutic opportunities, biotech's bumpy road to the market and elucidating the biochemical programs that support cancer initiation and progression. J Biol Med Science 1: e103.

79.A Heidari (2017) The design graphene-based nanosheets as a new nanomaterial in anti-cancer therapy and delivery of chemotherapeutics and biological nano drugs for liposomal anti-cancer nano drugs and gene delivery. Br Biomed Bull 5: 305.

80.A Heidari (2017) Integrative approach to biological networks for emerging roles of proteomics, genomics and transcriptomics in the discovery and validation of human colorectal cancer biomarkers from DNA/ RNA sequencing data under synchrotron radiation. Transcriptomics 5: e117.

81.A Heidari (2017) Elimination of the heavy metals toxicity and diseases in disruption of extracellular matrix (ECM) proteins and cell adhesion intelligent nanomolecules adjustment in cancer metastases using metalloenzymes and under synchrotron radiation. Lett Health Biol Sci 2: 1-4.

82.A Heidari (2017) Treatment of breast cancer brain metastases through a targeted nanomolecule drug delivery system based on dopamine functionalized multi-wall carbon nanotubes (MWCNTs) coated with nano graphene oxide (GO) and protonated polyaniline (PANI) in situ during the polymerization of aniline autogenic nanoparticles for the delivery of anti-cancer nano drugs under synchrotron radiation. BrJ Res 4: 16.

83.A Heidari (2017) Sedative, analgesic and ultrasoundmediated gastrointestinal nano drugs delivery for gastrointestinal endoscopic procedure, nano druginduced gastrointestinal disorders and nano drug treatment of gastric acidity. Res Rep Gastroenterol 1: 1 .

84.A Heidari (2017) Synthesis, pharmacokinetics, pharmacodynamics, dosing, stability, safety and efficacy of orphan nano drugs to treat high cholesterol and related conditions and to prevent cardiovascular disease under synchrotron radiation. J Pharm Sci Emerg Drugs 5: 1.

85.A Heidari (2017) Non-Linear compact proton synchrotrons to improve human cancer cells and tissues treatments and diagnostics through particle therapy accelerators with monochromatic microbeams. Cell Immunol Serum Biol 3: 115-119.

86.A Heidari (2017) Design of targeted metal chelation therapeutics nanocapsules as colloidal carriers and blood-brain barrier (BBB) translocation to targeted deliver anti-cancer nano drugs into the human brain to treat alzheimer's disease under synchrotron radiation. J Nanotechnol Material Sci 4: 1-5.

87.R Gobato, A Heidari (2017) Calculations using quantum chemistry for inorganic molecule simulation BeLi $\mathrm{i}_{2} \mathrm{SeSi}$. Science Journal of Analytical Chemistry 5: 76-85.

88. A Heidari (2017) Different high-resolution simulations of medical, medicinal, clinical, pharmaceutical and therapeutics oncology of human lung cancer translational anti-cancer nano drugs delivery treatment process under synchrotron and $\mathrm{x}$-ray radiations. J Med Oncol 1: 1.

89.A Heidari (2017) A modern ethnomedicinal technique for transformation, prevention and treatment of human malignant gliomas tumors into human benign gliomas tumors under synchrotron radiation. Am J Ethnomed 4: 1-10.

90.A Heidari (2017) Active targeted nanoparticles for anti-cancer nano drugs delivery across the bloodbrain barrier for human brain cancer treatment, multiple sclerosis (MS) and alzheimer's diseases 
using chemical modifications of anti-cancer nano drugs or drug-nanoparticles through zika virus (ZIKV) nanocarriers under synchrotron radiation. J Med Chem Toxicol 2: 1-5.

91.A Heidari (2017) Investigation of medical, medicinal, clinical and pharmaceutical applications of estradiol, mestranol (norlutin), norethindrone (NET), norethisterone acetate (NETA), norethisterone enanthate (NETE) and testosterone nanoparticles as biological imaging, cell labeling, anti-microbial agents and anti-cancer nano drugs in nanomedicines based drug delivery systems for anti-cancer targeting and treatment. Parana Journal of Science and Education (PJSE) 3: 10-19.

92.A Heidari (2017) A comparative computational and experimental study on different vibrational biospectroscopy methods, techniques and applications for human cancer cells in tumor tissues simulation, modeling, research, diagnosis and treatment. Open J Anal Bioanal Chem 1: 014-020.

93.A Heidari (2017) Combination of DNA/RNA ligands and linear/non-linear visible-synchrotron radiationdriven $\mathrm{n}$-doped ordered mesoporous cadmium oxide (CdO) nanoparticles photocatalysts channels resulted in an interesting synergistic effect enhancing catalytic anti-cancer activity. Enz Eng 6: 1.

94.A Heidari (2017) Modern approaches in designing ferritin, ferritin light chain, transferrin, beta-2 transferrin and bacterioferritin-based anti-cancer nano drugs encapsulating nanosphere as dna-binding proteins from starved cells (DPS). Mod Appro Drug Des 1: 1-5.

95.A Heidari (2017) Potency of human interferon $\beta$-1a and human interferon $\beta-1 b$ in enzymotherapy, immunotherapy, chemotherapy, radiotherapy, hormone therapy and targeted therapy of encephalomyelitis disseminate/multiple sclerosis (ms) and hepatitis A, B, C, D, E, F and G virus enter and targets liver cells. J Proteomics Enzymol 6: 1.

96.A Heidari (2017) Transport therapeutic active targeting of human brain tumors enable anti-cancer nanodrugs delivery across the blood-brain barrier (BBB) to treat brain diseases using nanoparticles and nanocarriers under synchrotron radiation. J Pharm Pharmaceutics 4: 1-5.

97.A Heidari, C Brown (2017) Combinatorial therapeutic approaches to DNA/RNA and benzylpenicillin (penicillin g), fluoxetine hydrochloride (prozac and sarafem), propofol (diprivan), acetylsalicylic acid (ASA) (Aspirin), naproxen sodium (aleve and naprosyn) and dextromethamphetamine nanocapsules with surface conjugated dna/rna to targeted nano drugs for enhanced anti-cancer efficacy and targeted cancer therapy using nano drugs delivery systems. Ann Adv Chem 1: 061-069.

98.A Heidari (2017) High-resolution simulations of human brain cancer translational nano drugs delivery treatment process under synchrotron radiation. J Transl Res 1: 1-3.

99.A Heidari (2017) Investigation of anti-cancer nano drugs' effects' trend on human pancreas cancer cells and tissues prevention, diagnosis and treatment process under synchrotron and $\mathrm{X}$-ray radiations with the passage of time using mathematica. Current Trends Anal Bioanal Chem 1: 36-41.

100.A Heidari (2017) Pros and cons controversy on molecular imaging and dynamics of doublestandard DNA/RNA of human preserving stem cellsbinding nano molecules with androgens/anabolic steroids (AAS) or testosterone derivatives through tracking of helium-4 nucleus (Alpha Particle) using synchrotron radiation. Arch Biotechnol Biomed 1: 067-0100.

101.A Heidari (2017) Visualizing metabolic changes in probing human cancer cells and tissues metabolism using vivo ${ }^{1} \mathrm{H}$ or Proton NMR, ${ }^{13} \mathrm{C}$ NMR, ${ }^{15} \mathrm{~N}$ NMR and ${ }^{31} \mathrm{P}$ NMR spectroscopy and self-organizing maps under synchrotron radiation. SOJ Mater Sci Eng 5: 1-6.

102.A Heidari (2017) Cavity ring-down spectroscopy (CRDS), circular dichroism spectroscopy, cold vapour atomic fluorescence spectroscopy and correlation spectroscopy comparative study on malignant and benign human cancer cells and tissues with the passage of time under synchrotron radiation. Enliven: Challenges Cancer Detect Ther 4: e001.

103.A Heidari (2017) Laser spectroscopy, laser-induced breakdown spectroscopy and laser-induced plasma spectroscopy comparative study on malignant and benign human cancer cells and tissues with the passage of time under synchrotron radiation. Int J Hepatol Gastroenterol 3: 079-084.

104.A Heidari (2017) Time-resolved spectroscopy and time-stretch spectroscopy comparative study on malignant and benign human cancer cells and tissues with the passage of time under synchrotron radiation. Enliven: Pharmacovigilance and Drug Safety 4: e001.

105.A Heidari (2017) Overview of the role of vitamins in 
reducing negative effect of Decapeptyl (Triptorelin Acetate or Pamoate Salts) on prostate cancer cells and tissues in prostate cancer treatment process through transformation of malignant prostate tumors into benign prostate tumors under synchrotron radiation. Open J Anal Bioanal Chem 1: 021-026.

106.A Heidari (2017) Electron Phenomenological Spectroscopy, Electron Paramagnetic Resonance (EPR) Spectroscopy and Electron Spin Resonance (ESR) Spectroscopy comparative study on malignant and benign human cancer cells and tissues with the passage of time under synchrotron radiation. Austin J Anal Pharm Chem 4: 1091.

107.A Heidari (2017) Therapeutic nanomedicine different high-resolution experimental images and computational simulations for human brain cancer cells and tissues using nanocarriers deliver DNA/ RNA to brain tumors under synchrotron radiation with the passage of time using mathematica and MATLAB. Madridge J Nano Tech Sci 2: 77-83.

108. A Heidari (2017) A consensus and prospective study on restoring Cadmium Oxide ( $\mathrm{CdO}$ ) nanoparticles sensitivity in recurrent ovarian cancer by extending the Cadmium Oxide (CdO) nanoparticles-free interval using synchrotron radiation therapy as antibody-drug conjugate for the treatment of limited-stage small cell diverse epithelial cancers. Cancer Clin Res Rep 1: e001.

109. A Heidari (2017) A novel and modern experimental imaging and spectroscopy comparative study on malignant and benign human cancer cells and tissues with the passage of time under white synchrotron radiation. Cancer Sci Res Open Access 4: 1-8.

110.A Heidari (2017) Different high-resolution simulations of medical, medicinal, clinical, pharmaceutical and therapeutics oncology of human breast cancer translational nano drugs delivery treatment process under synchrotron and X-Ray radiations. J Oral Cancer Res 1: 12-17.

111.A Heidari (2017) Vibrational Decihertz (dHz), Centihertz $(\mathrm{cHz})$, Millihertz $(\mathrm{mHz})$, Microhertz $(\mu \mathrm{Hz})$, Nanohertz $(\mathrm{nHz})$, Picohertz $(\mathrm{pHz})$, Femtohertz $(\mathrm{fHz})$, Attohertz $(\mathrm{aHz})$, Zeptohertz $(\mathrm{zHz})$ and Yoctohertz $(\mathrm{yHz})$ imaging and spectroscopy comparative study on malignant and benign human cancer cells and tissues under synchrotron radiation. International Journal of Biomedicine 7: 335-340.

112.A Heidari (2017) Force spectroscopy and fluorescence spectroscopy comparative study on malignant and benign human cancer cells and tissues with the passage of time under synchrotron radiation. EC Cancer 2: 239-246.

113.A Heidari (2017) Photoacoustic spectroscopy, photoemission spectroscopy and photothermal spectroscopy comparative study on malignant and benign human cancer cells and tissues with the passage of time under synchrotron radiation. BAOJ Cancer Res Ther 3: 045-052.

114.A Heidari (2017) J-Spectroscopy, Exchange Spectroscopy (EXSY), Nuclear Overhauser Effect Spectroscopy (NOESY) and Total Correlation Spectroscopy (TOCSY) comparative study on malignant and benign human cancer cells and tissues under synchrotron radiation. EMS Eng Sci J 1: 006-013.

115.A Heidari (2017) Neutron spin echo spectroscopy and spin noise spectroscopy comparative study on malignant and benign human cancer cells and tissues with the passage of time under synchrotron radiation. Int J Biopharm Sci 1: 103-107.

116.A Heidari (2017) Vibrational Decahertz (daHz), Hectohertz ( $\mathrm{hHz})$, Kilohertz $(\mathrm{kHz})$, Megahertz $(\mathrm{MHz})$, Gigahertz (GHz), Terahertz ( $\mathrm{THz})$, Petahertz $(\mathrm{PHz})$, Exahertz (EHz), Zettahertz ( $\mathrm{ZHz})$ and Yottahertz $(\mathrm{YHz})$ imaging and spectroscopy comparative study on malignant and benign human cancer cells and tissues under synchrotron radiation. Madridge J Anal Sci Instrum 2: 41-46.

117.A Heidari (2018) Two-dimensional infrared correlation spectroscopy, linear two-dimensional infrared spectroscopy and non-linear twodimensional infrared spectroscopy comparative study on malignant and benign human cancer cells and tissues under synchrotron radiation with the passage of time. J Mater Sci Nanotechnol 6: 101.

118. A Heidari (2018) Fourier Transform Infrared (FTIR) Spectroscopy, Near-Infrared Spectroscopy (NIRS) and Mid-Infrared Spectroscopy (MIRS) comparative study on malignant and benign human cancer cells and tissues under synchrotron radiation with the passage of time. Int J Nanotechnol Nanomed 3: 1-6.

119.A Heidari (2018) Infrared photo dissociation spectroscopy and infrared correlation table spectroscopy comparative study on malignant and benign human cancer cells and tissues under synchrotron radiation with the passage of time. Austin Pharmacol Pharm 3: 1011.

120.A Heidari (2017) Novel and transcendental 
prevention, diagnosis and treatment strategies for investigation of interaction among human blood cancer cells, tissues, tumors and metastases with synchrotron radiation under anti-cancer nano drugs delivery efficacy using MATLAB modeling and simulation. Madridge J Nov Drug Res 1: 18-24.

121.A Heidari (2018) Comparative study on malignant and benign human cancer cells and tissues with the passage of time under synchrotron radiation. Open Access J Trans Med Res 2: 4-9.

122.MRR Gobato, R Gobato, A Heidari (2018) Planting of jaboticaba trees for landscape repair of degraded area. Landscape Architecture and Regional Planning 3: 1-9.

123.A Heidari (2018) Fluorescence spectroscopy, phosphorescence spectroscopy and luminescence spectroscopy comparative study on malignant and benign human cancer cells and tissues under synchrotron radiation with the passage of time. SM J Clin Med Imaging 4: 1018.

124.A Heidari (2018) Nuclear Inelastic Scattering Spectroscopy (NISS) and Nuclear Inelastic Absorption Spectroscopy (NIAS) comparative study on malignant and benign human cancer cells and tissues under synchrotron radiation. Int J Pharm Sci 2: 1-14.

125.A Heidari (2018) X-Ray Diffraction (XRD), Powder $X$-Ray Diffraction (PXRD) and Energy-Dispersive $X$-Ray Diffraction (EDXRD) comparative study on malignant and benign human cancer cells and tissues under synchrotron radiation. J Oncol Res 2: 1-14.

126.A Heidari (2018) Correlation two-dimensional Nuclear Magnetic Resonance (NMR) (2D-NMR) (COSY) imaging and spectroscopy comparative study on malignant and benign human cancer cells and tissues under synchrotron radiation. EMS Can Sci.

127.A Heidari (2018) Thermal spectroscopy, photothermal spectroscopy, thermal microspectroscopy, photothermal microspectroscopy, thermal macrospectroscopy and photothermal macrospectroscopy comparative study on malignant and benign human cancer cells and tissues with the passage of time under synchrotron radiation. SM J Biometrics Biostat 3: 1024.

128. A Heidari (2018) A modern and comprehensive experimental biospectroscopic comparative study on human common cancers' cells, tissues and tumors before and after synchrotron radiation therapy. Open Acc J Oncol Med 1.

129.A Heidari (2018) Heteronuclear Correlation Experiments such as Heteronuclear Single-Quantum Correlation Spectroscopy (HSQC), Heteronuclear Multiple-Quantum Correlation Spectroscopy (HMQC) and Heteronuclear Multiple-Bond Correlation Spectroscopy (HMBC) comparative study on malignant and benign human endocrinology and thyroid cancer cells and tissues under synchrotron radiation. J Endocrinol Thyroid Res 3: 555603.

130.A Heidari (2018) Nuclear Resonance Vibrational Spectroscopy (NRVS), Nuclear Inelastic Scattering Spectroscopy (NISS), Nuclear Inelastic Absorption Spectroscopy (NIAS) and Nuclear Resonant Inelastic X-Ray Scattering Spectroscopy (NRIXSS) comparative study on malignant and benign human cancer cells and tissues under synchrotron radiation. Int J Bioorg Chem Mol Biol 6: 1-5.

131. A Heidari (2018) A novel and modern experimental approach to vibrational circular dichroism spectroscopy and video spectroscopy comparative study on malignant and benign human cancer cells and tissues with the passage of time under white and monochromatic synchrotron radiation. Glob J Endocrinol Metab 1.

132.A Heidari (2018) Pros and Cons Controversy on heteronuclear correlation experiments such as Heteronuclear Single-Quantum Correlation Spectroscopy (HSQC), Heteronuclear Multiple-Quantum Correlation Spectroscopy (HMQC) and Heteronuclear Multiple-Bond Correlation Spectroscopy (HMBC) comparative study on malignant and benign human cancer cells and tissues under synchrotron radiation. EMS Pharma J 1: 002-008.

133.A Heidari (2018) A modern comparative and comprehensive experimental biospectroscopic study on different types of infrared spectroscopy of malignant and benign human cancer cells and tissues with the passage of time under synchrotron radiation. J Analyt Molecul Tech 3: 8.

134.A Heidari (2018) Investigation of cancer types using synchrotron technology for proton beam therapy: An experimental biospectroscopic comparative study. European Modern Studies Journal 2: 13-29.

135.A Heidari (2018) Saturated spectroscopy and unsaturated spectroscopy comparative study on malignant and benign human cancer cells and tissues with the passage of time under synchrotron radiation. Imaging J Clin Medical Sci 5: 001-007.

136.A Heidari (2018) Small-Angle Neutron Scattering 
(SANS) and Wide-Angle X-Ray Diffraction (WAXD) comparative study on malignant and benign human cancer cells and tissues under synchrotron radiation. Int J Bioorg Chem Mol Biol 6: 1-6.

137.A Heidari (2018) Investigation of bladder cancer, breast cancer, colorectal cancer, endometrial cancer, kidney cancer, leukemia, liver, lung cancer, melanoma, non-hodgkin lymphoma, pancreatic cancer, prostate cancer, thyroid cancer and non-melanoma skin cancer using synchrotron technology for proton beam therapy: An experimental biospectroscopic comparative study. Ther Res Skin Dis 1.

138.A Heidari (2018) Attenuated Total Reflectance FourierTransform Infrared (ATR-FTIR) Spectroscopy, Micro-Attenuated Total Reflectance Fourier Transform Infrared (Micro-ATR-FTIR) Spectroscopy and Macro-Attenuated Total Reflectance Fourier Transform Infrared (Macro-ATR-FTIR) spectroscopy comparative study on malignant and benign human cancer cells and tissues under synchrotron radiation with the passage of time. International Journal of Chemistry Papers 2: 1-12.

139.A Heidari (2018) Mössbauer spectroscopy, mössbauer emission spectroscopy and ${ }^{57} \mathrm{Fe}$ mössbauer spectroscopy comparative study on malignant and benign human cancer cells and tissues under synchrotron radiation. Acta Scientific Cancer Biology 2.3: 17-20.

140.A Heidari (2018) Comparative study on malignant and benign human cancer cells and tissues under synchrotron radiation with the passage of time. Organic \& Medicinal Chem IJ 6: 555676.

141.A Heidari (2018) Correlation spectroscopy, exclusive correlation spectroscopy and total correlation spectroscopy comparative study on malignant and benign human aids-related cancers cells and tissues with the passage of time under synchrotron radiation. Int J Bioanal Biomed 2: 001-007.

142.A Heidari (2018) Biomedical instrumentation and applications of biospectroscopic methods and techniques in malignant and benign human cancer cells and tissues studies under synchrotron radiation and anti-cancer nano drugs delivery. Am J Nanotechnol Nanomed 1: 001-009.

143. A Heidari (2018) Vivo ${ }^{1} \mathrm{H}$ or Proton NMR, ${ }^{13} \mathrm{C}$ NMR, ${ }^{15} \mathrm{~N}$ NMR and ${ }^{31} \mathrm{P}$ NMR spectroscopy comparative study on malignant and benign human cancer cells and tissues under synchrotron radiation. Ann Biomet Biostat 1: 1001.
144.A Heidari (2018) Grazing-Incidence Small-Angle Neutron Scattering (GISANS) and Grazing-Incidence $X$-Ray Diffraction (GIXD) comparative study on malignant and benign human cancer cells, tissues and tumors under synchrotron radiation. Ann Cardiovasc Surg 1: 1006.

145. A Heidari (2018) Adsorption Isotherms and Kinetics of Multi-Walled Carbon Nanotubes (MWCNTs), Boron Nitride Nanotubes (BNNTs), Amorphous Boron Nitride Nanotubes (a-BNNTs) and Hexagonal Boron Nitride Nanotubes (h-BNNTs) for eliminating carcinoma, sarcoma, lymphoma, leukemia, germ cell tumor and blastoma cancer cells and tissues. Clin Med Rev Case Rep 5: 201.

146.A Heidari (2018) Correlation Spectroscopy (COSY), Exclusive Correlation Spectroscopy (ECOSY), Total Correlation Spectroscopy (TOCSY), Incredible Natural-Abundance Double-Quantum Transfer Experiment (INADEQUATE), Heteronuclear Single-Quantum Correlation Spectroscopy (HSQC), Heteronuclear Multiple-Bond Correlation Spectroscopy (HMBC), Nuclear Overhauser Effect Spectroscopy (NOESY) and Rotating Frame Nuclear Overhauser Effect Spectroscopy (ROESY) comparative study on malignant and benign human cancer cells and tissues under synchrotron radiation. Acta Scientific Pharmaceutical Sciences 2: 30-35.

147.A Heidari (2018) Small-Angle X-Ray Scattering (SAXS), Ultra-Small Angle X-Ray Scattering (USAXS), Fluctuation X-Ray Scattering (FXS), Wide-Angle $X$-Ray Scattering (WAXS), Grazing-Incidence SmallAngle X-Ray Scattering (GISAXS), Grazing-Incidence Wide-Angle X-Ray Scattering (GIWAXS), SmallAngle Neutron Scattering (SANS), Grazing-Incidence Small-Angle Neutron Scattering (GISANS), X-Ray Diffraction (XRD), Powder X-Ray Diffraction (PXRD), Wide-Angle X-Ray Diffraction (WAXD), GrazingIncidence X-Ray Diffraction (GIXD) and EnergyDispersive X-Ray Diffraction (EDXRD) comparative study on malignant and benign human cancer cells and tissues under synchrotron radiation. Oncol Res Rev 1: 1-10.

148.A Heidari (2018) Pump-probe spectroscopy and transient grating spectroscopy comparative study on malignant and benign human cancer cells and tissues with the passage of time under synchrotron radiation. Adv Material Sci Engg 2: 1-7.

149.A Heidari (2018) Grazing-Incidence Small-Angle X-Ray Scattering (GISAXS) and Grazing-Incidence Wide-Angle X-Ray Scattering (GIWAXS) comparative 
study on malignant and benign human cancer cells and tissues under synchrotron radiation. Insights Pharmacol Pharm Sci 1: 1-8.

150.A Heidari (2018) Acoustic spectroscopy, acoustic resonance spectroscopy and auger spectroscopy comparative study on anti-cancer nano drugs delivery in malignant and benign human cancer cells and tissues with the passage of time under synchrotron radiation. Nanosci Technol 5: 1-9.

151.A Heidari (2018) Niobium, Technetium, Ruthenium, Rhodium, Hafnium, Rhenium, Osmium and Iridium Ions Incorporation into the Nano Polymeric Matrix (NPM) by Immersion of the Nano Polymeric Modified Electrode (NPME) as molecular enzymes and drug targets for human cancer cells, tissues and tumors treatment under synchrotron and synchrocyclotron radiations. Nanomed Nanotechnol 3: 000138.

152.A Heidari (2018) Homonuclear Correlation Experiments such as Homonuclear Single-Quantum Correlation Spectroscopy (HSQC), Homonuclear Multiple-Quantum Correlation Spectroscopy (HMQC) and Homonuclear Multiple-Bond Correlation Spectroscopy (HMBC) comparative study on malignant and benign human cancer cells and tissues under synchrotron radiation. Austin J Proteomics Bioinform \& Genomics 5: 1024.

153. A Heidari (2018) Atomic Force Microscopy Based Infrared (AFM-IR) spectroscopy and nuclear resonance vibrational spectroscopy comparative study on malignant and benign human cancer cells and tissues under synchrotron radiation with the passage of time. J Appl Biotechnol Bioeng 5: 142148.

154.A Heidari (2018) Time-dependent vibrational spectral analysis of malignant and benign human cancer cells and tissues under synchrotron radiation. J Cancer Oncol 2: 000124.

155. A Heidari (2018) Palauamine and olympiadane nano molecules incorporation into the Nano Polymeric Matrix (NPM) by immersion of the Nano Polymeric Modified Electrode (NPME) as molecular enzymes and drug targets for human cancer cells, tissues and tumors treatment under synchrotron and synchrocyclotron radiations. Arc Org Inorg Chem Sci 3.

156.R Gobato, A Heidari (2018) Infrared spectrum and sites of action of sanguinarine by molecular mechanics and ab initio methods. International Journal of Atmospheric and Oceanic Sciences 2: 1-9.

157.A Heidari (2018) Angelic acid, diabolic acids, draculin and miraculin nano molecules incorporation into the Nano Polymeric Matrix (NPM) by Immersion of the Nano Polymeric Modified Electrode (NPME) as molecular enzymes and drug targets for human cancer cells, tissues and tumors treatment under synchrotron and synchrocyclotron radiations. Med \& Analy Chem Int J 2: 000111.

158.A Heidari (2018) Gamma Linolenic Methyl Ester, 5-Heptadeca-5,8,11-Trienyl 1,3,4-Oxadiazole-2Thiol, Sulphoquinovosyl Diacyl Glycerol, Ruscogenin, Nocturnoside B, Protodioscine B, Parquisoside-B, Leiocarposide, Narangenin, 7-Methoxy Hespertin, Lupeol, Rosemariquinone, Rosmanol and Rosemadiol Nano Molecules Incorporation into the Nano Polymeric Matrix (NPM) by Immersion of the Nano Polymeric Modified Electrode (NPME) as molecular enzymes and drug targets for human cancer cells, tissues and tumors treatment under synchrotron and synchrocyclotron radiations. Int J Pharma Anal Acta 2: 007-014.

159.A Heidari (2018) Fourier Transform Infrared (FTIR) Spectroscopy, Attenuated Total Reflectance Fourier Transform Infrared (ATR-FTIR) Spectroscopy, MicroAttenuated Total Reflectance Fourier Transform Infrared (Micro-ATR-FTIR) Spectroscopy, MacroAttenuated Total Reflectance Fourier Transform Infrared (Macro-ATR-FTIR) Spectroscopy, twodimensional infrared correlation spectroscopy, linear two-dimensional infrared spectroscopy, non-linear two-dimensional infrared spectroscopy, Atomic Force Microscopy Based Infrared (AFMIR) spectroscopy, infrared photodissociation spectroscopy, infrared correlation table spectroscopy, Near-Infrared Spectroscopy (NIRS), Mid-Infrared Spectroscopy (MIRS), nuclear resonance vibrational spectroscopy, thermal infrared spectroscopy and photothermal infrared spectroscopy comparative study on malignant and benign human cancer cells and tissues under synchrotron radiation with the passage of time. Glob Imaging Insights 3: 1-14.

160.A Heidari (2018) Heteronuclear Single-Quantum Correlation Spectroscopy (HSQC) and Heteronuclear Multiple-Bond Correlation Spectroscopy (HMBC) comparative study on malignant and benign human cancer cells, tissues and tumors under synchrotron and synchrocyclotron radiations. Chronicle of Medicine and Surgery 2: 144-156.

161.A Heidari (2018) Tetrakis [3, 5-bis (Trifluoromethyl) Phenyl] Borate (BARF)-Enhanced Precatalyst Preparation Stabilization and Initiation (EPPSI) Nano Molecules. Medical Research and Clinical Case Reports 


\section{2: $113-126$}

162.A Heidari (2018) Sydnone, münchnone, montréalone, mogone, montelukast, quebecol and palau'amine-Enhanced Precatalyst Preparation Stabilization and Initiation (EPPSI) Nano Molecules. Sur Cas Stud Op Acc J 1.

163. A Heidari (2018) Fornacite, orotic acid, rhamnetin, Sodium Ethyl Xanthate (SEX) and spermine (spermidine or polyamine) nanomolecules incorporation into the Nanopolymeric Matrix (NPM). International Journal of Biochemistry and Biomolecules 4: 1-19.

164.A Heidari, R Gobato (2018) Putrescine, cadaverine, spermine and Spermidine-Enhanced Precatalyst Preparation Stabilization and Initiation (EPPSI) nano molecules. Parana Journal of Science and Education (PJSE) 4: 1-14.

165. A Heidari (2018) Cadaverine (1,5-Pentanediamine or Pentamethylenediamine), Diethyl Azodicarboxylate (DEAD or DEADCAT) and Putrescine (Tetramethylenediamine) Nano Molecules Incorporation into the Nano Polymeric Matrix (NPM) by Immersion of the Nano Polymeric Modified Electrode (NPME) as Molecular Enzymes and Drug Targets for Human Cancer Cells, Tissues and Tumors Treatment under Synchrotron and Synchrocyclotron Radiations. Hiv and Sexual Health Open Access Open Journal 1: 4-11.

166.A Heidari (2018) Improving the performance of nano-endofullerenes in polyaniline nanostructurebased biosensors by covering californium colloidal nanoparticles with multi-walled carbon nanotubes. Journal of Advances in Nanomaterials 3: 1-28.

167.R Gobato, A Heidari (2018) Molecular mechanics and quantum chemical study on sites of action of sanguinarine using vibrational spectroscopy based on molecular mechanics and quantum chemical calculations. Malaysian Journal of Chemistry 20: 1-23.

168.A Heidari (2018) Vibrational biospectroscopic studies on anti-cancer nanopharmaceuticals (Part I). Malaysian Journal of Chemistry 20: 33-73.

169.A Heidari (2018) Vibrational biospectroscopic studies on anti-cancer nanopharmaceuticals (Part II). Malaysian Journal of Chemistry 20: 74-117.

170.A Heidari (2018) Uranocene $\left(\mathrm{U}\left(\mathrm{C}_{8} \mathrm{H}_{8}\right)_{2}\right)$ and Bis(Cyclooctatetraene)Iron $\left(\mathrm{Fe}\left(\mathrm{C}_{8} \mathrm{H}_{8}\right)_{2}\right.$ or $\left.\mathrm{Fe}(\mathrm{COT})_{2}\right)$ Enhanced Precatalyst Preparation Stabilization and Initiation (EPPSI) Nano Molecules. Chemistry Reports 1: 1-16.
171.A Heidari (2018) Biomedical systematic and emerging technological study on human malignant and benign cancer cells and tissues biospectroscopic analysis under synchrotron radiation. Glob Imaging Insights 3: 1-7.

172.A Heidari (2018) Deep-level transient spectroscopy and X-Ray Photoelectron Spectroscopy (XPS) comparative study on malignant and benign human cancer cells and tissues with the passage of time under synchrotron radiation. Res Dev Material Sci 7.

173.A Heidari (2018) C70-Carboxyfullerenes nano molecules incorporation into the Nano Polymeric Matrix (NPM) by Immersion of the Nano Polymeric Modified Electrode (NPME) as molecular enzymes and drug targets for human cancer cells, tissues and tumors treatment under synchrotron and synchrocyclotron radiations. Glob Imaging Insights 3: 1-7.

174.A Heidari (2018) The effect of temperature on Cadmium Oxide ( $\mathrm{CdO}$ ) nanoparticles produced by synchrotron radiation in the human cancer cells, tissues and tumors. International Journal of Advanced Chemistry 6: 140-156.

175.A Heidari (2018) A Clinical and Molecular Pathology Investigation of Correlation Spectroscopy (COSY), Exclusive Correlation Spectroscopy (ECOSY), Total Correlation Spectroscopy (TOCSY), Heteronuclear Single-Quantum Correlation Spectroscopy (HSQC) and Heteronuclear Multiple-Bond Correlation Spectroscopy (HMBC) comparative study on malignant and benign human cancer cells, tissues and tumors under synchrotron and synchrocyclotron radiations using cyclotron versus synchrotron, synchrocyclotron and the Large Hadron Collider (LHC) for delivery of proton and helium ion (charged particle) beams for oncology radiotherapy. European Journal of Advances in Engineering and Technology 5: 414-426.

176. A Heidari (2018) Nano Molecules Incorporation into the Nano Polymeric Matrix (NPM) by Immersion of the Nano Polymeric Modified Electrode (NPME) as molecular enzymes and drug targets for human cancer cells, tissues and tumors treatment under synchrotron and synchrocyclotron radiations. J Oncol Res 1: 1-20.

177.A Heidari (2018) Use of molecular enzymes in the treatment of chronic disorders. Canc Oncol Open Access J 1: 12-15.

178.A Heidari (2018) Vibrational biospectroscopic study 
and chemical structure analysis of unsaturated polyamides nanoparticles as anti-cancer polymeric nanomedicines using synchrotron radiation. International Journal of Advanced Chemistry 6: 167-189.

179.A Heidari (2018) Adamantane, irene, naftazone and pyridine-enhanced precatalyst Preparation Stabilization and Initiation (PEPPSI) nano molecules. Madridge J Nov Drug Res 2: 61-67.

180.A Heidari (2018) Heteronuclear Single-Quantum Correlation Spectroscopy (HSQC) and Heteronuclear Multiple-Bond Correlation Spectroscopy (HMBC) comparative study on malignant and benign human cancer cells and tissues with the passage of time under synchrotron radiation. Madridge J Nov Drug Res 2: 68-74.

181.A Heidari, R Gobato (2018) A novel approach to reduce toxicities and to improve bioavailabilities of DNA/RNA of Human CancerCells-Containing Cocaine (Coke), Lysergide (Lysergic Acid Diethyl Amide or LSD), $\Delta^{9}$-Tetrahydrocannabinol (THC) [(-)-trans- $\Delta^{9}$ Tetrahydrocannabinol], Theobromine (Xantheose), Caffeine, Aspartame (APM) (NutraSweet) and Zidovudine (ZDV) [Azidothymidine (AZT)] as anticancer nano drugs by coassembly of dual anticancer nano drugs to Inhibit DNA/RNA of human cancer cells drug resistance. Parana Journal of Science and Education 4: 1-17.

182. A Heidari, R Gobato (2018) Ultraviolet Photoelectron Spectroscopy (UPS) and Ultraviolet-Visible (UVVis) spectroscopy comparative study on malignant and benign human cancer cells and tissues with the passage of time under synchrotron radiation. Parana Journal of Science and Education 4: 18-33.

183.R Gobato, A Heidari, A Mitra (2018) The creation of $\mathrm{C}_{13} \mathrm{H}_{20} \mathrm{BeLi}{ }_{2} \mathrm{SeSi}$. The proposal of a bio-inorganic molecule, using $A b$ initio methods for the genesis of a nano membrane. Arc Org Inorg Chem Sci 3.

184.R Gobato, A Heidari (2018) Using the quantum chemistry for genesis of a nano biomembrane with a combination of the elements $\mathrm{Be}, \mathrm{Li}, \mathrm{Se}, \mathrm{Si}, \mathrm{C}$ and H. J Nanomed Res 7: 241-252.

185.A Heidari (2018) Bastadins and BastaranesEnhanced Precatalyst Preparation Stabilization and Initiation (EPPSI) nano molecules. Glob Imaging Insights 3: 1-7.

186.A Heidari (2018) Fucitol, Pterodactyladiene, DEAD or DEADCAT (DiEthyl AzoDiCArboxylaTe), Skatole, the NanoPutians, Thebacon, Pikachurin, Tie Fighter, Spermidine and Mirasorvone Nano
Molecules Incorporation into the Nano Polymeric Matrix (NPM) by Immersion of the Nano Polymeric Modified Electrode (NPME) as molecular enzymes and drug targets for human cancer cells, tissues and tumors treatment under synchrotron and synchrocyclotron radiations. Glob Imaging Insights 3: 1-8.

187.E Dadvar, A Heidari (2018) A review on separation techniques of Graphene Oxide (GO)/base on hybrid polymer membranes for eradication of dyes and oil compounds: Recent progress in Graphene Oxide (GO)/base on polymer membranes-related nanotechnologies. Clin Med Rev Case Rep 5: 228.

188. A Heidari, R Gobato (2018) First-Time Simulation of Deoxyuridine Monophosphate (dUMP) (Deoxyuridylic Acid or Deoxyuridylate) and Vomitoxin (Deoxynivalenol (DON)) $((3 \alpha, 7 \alpha)-3,7,15-$ Trihydroxy12,13-Epoxytrichothec-9-En-8-One)-Enhanced Precatalyst Preparation Stabilization and Initiation (EPPSI) Nano Molecules Incorporation into the Nano Polymeric Matrix (NPM) by Immersion of the Nano Polymeric Modified Electrode (NPME) as molecular enzymes and drug targets for human cancer cells, tissues and tumors treatment under synchrotron and synchrocyclotron radiations. Parana Journal of Science and Education 4: 46-67.

189.A Heidari (2018) Buckminsterfullerene (Fullerene), Bullvalene, Dickite and Josiphos Ligands Nano Molecules Incorporation into the Nano Polymeric Matrix (NPM) by Immersion of the Nano Polymeric Modified Electrode (NPME) as molecular enzymes and drug targets for human hematology and thromboembolic diseases prevention, diagnosis and treatment under synchrotron and synchrocyclotron radiations. Glob Imaging Insights 3: 1-7.

190.A Heidari (2018) Fluctuation X-Ray Scattering (FXS) and Wide-Angle X-Ray Scattering (WAXS) comparative study on malignant and benign human cancer cells and tissues under synchrotron radiation. Glob imaging insights 3: 1-7.

191.A Heidari (2018) A novel approach to Correlation Spectroscopy (COSY), Exclusive Correlation Spectroscopy (ECOSY), Total Correlation Spectroscopy (TOCSY), Incredible Natural-Abundance Double-Quantum Transfer Experiment (INADEQUATE), Heteronuclear Single-Quantum Correlation Spectroscopy (HSQC), Heteronuclear Multiple-Bond Correlation Spectroscopy (HMBC), Nuclear Overhauser Effect Spectroscopy (NOESY) and Rotating Frame Nuclear Overhauser Effect Spectroscopy (ROESY) comparative study on malignant and be- 
nign human cancer cells and tissues under synchrotron radiation. Glob Imaging Insights 3: 1-9.

192.A Heidari (2018) Terphenyl-Based Reversible Receptor with Rhodamine, Rhodamine-Based Molecular Probe, Rhodamine-Based Using the Spirolactam Ring Opening, Rhodamine B with Ferrocene Substituent, Calix[4]Arene-Based Receptor, Thioether + Aniline-Derived Ligand Framework Linked to a Fluorescein Platform, Mercuryfluor-1 (Flourescent Probe), N,N'-Dibenzyl-1,4,10,13-Tetraraoxa-7,16-Diazacyclooctadecane and Terphenyl-Based Reversible Receptor with Pyrene and Quinoline as the Fluorophores-Enhanced Precatalyst Preparation Stabilization and Initiation (EPPSI) nano molecules. Glob Imaging Insights 3: 1-9.

193.A Heidari (2018) Small-Angle X-Ray Scattering (SAXS), Ultra-Small Angle X-Ray Scattering (USAXS), Fluctuation X-Ray Scattering (FXS), Wide-Angle $X$-Ray Scattering (WAXS), Grazing-Incidence SmallAngle X-Ray Scattering (GISAXS), Grazing-Incidence Wide-Angle X-Ray Scattering (GIWAXS), SmallAngle Neutron Scattering (SANS), Grazing-Incidence Small-Angle Neutron Scattering (GISANS), X-Ray Diffraction (XRD), Powder X-Ray Diffraction (PXRD), Wide-Angle X-Ray Diffraction (WAXD), GrazingIncidence X-Ray Diffraction (GIXD) and EnergyDispersive X-Ray Diffraction (EDXRD) Comparative study on malignant and benign human cancer cells and tissues under synchrotron radiation. Glob Imaging Insights 3: 1-10.

194.A Heidari (2018) Nuclear Resonant Inelastic X-Ray Scattering Spectroscopy (NRIXSS) and Nuclear Resonance Vibrational Spectroscopy (NRVS) comparative study on malignant and benign human cancer cells and tissues under synchrotron radiation. Glob Imaging Insights 3: 1-7.

195.A Heidari (2018) Small-Angle X-Ray Scattering (SAXS) and Ultra-Small Angle X-Ray Scattering (USAXS) comparative study on malignant and benign human cancer cells and tissues under synchrotron radiation. Glob Imaging Insights 3: 1-7.

196. A Heidari (2018) Curious Chloride $\left(\mathrm{CmCl}_{3}\right)$ and Titanic Chloride $\left(\mathrm{TiCl}_{4}\right)$-Enhanced Precatalyst Preparation Stabilization and Initiation (EPPSI) nano molecules for cancer treatment and cellular therapeutics. J Cancer Research and Therapeutic Interventions 1: 01-10.

197.R Gobato, MRR Gobato, A Heidari, A Mitra (2018) Spectroscopy and dipole moment of the molecule $\mathrm{C}_{13} \mathrm{H}_{20} \mathrm{BeLi}_{2} \mathrm{SeSi}$ via quantum chemistry using $\mathrm{Ab}$ Initio, Hartree-Fock Method in the Base Set CC-
pVTZ and 6-311G**(3df, 3pd). Arc Org Inorg Chem Sci 3: 402-409.

198.A Heidari (2018) $C_{60}$ and $C_{70}$-Encapsulating Carbon Nanotubes Incorporation into the Nano Polymeric Matrix (NPM) by Immersion of the Nano Polymeric Modified Electrode (NPME) as molecular enzymes and drug targets for human cancer cells, tissues and tumors treatment under synchrotron and synchrocyclotron radiations. Integr Mol Med 5: 1-9.

199.A Heidari (2018) Two-Dimensional (2D) ${ }^{1} \mathrm{H}$ or Proton NMR, ${ }^{13} \mathrm{C}$ NMR, ${ }^{15} \mathrm{~N}$ NMR and ${ }^{31} \mathrm{P}$ NMR spectroscopy comparative study on malignant and benign human cancer cells and tissues under synchrotron radiation with the passage of time. Glob Imaging Insights 3: 1-8.

200.A Heidari (2018) FT-Raman Spectroscopy, Coherent Anti-Stokes Raman Spectroscopy (CARS) and Raman Optical Activity Spectroscopy (ROAS) comparative study on malignant and benign human cancer cells and tissues with the passage of time under synchrotron radiation. Glob Imaging Insights 3: 1-8.

201.A Heidari (2018) A modern and comprehensive investigation of Inelastic Electron Tunneling Spectroscopy (IETS) and scanning tunneling spectroscopy on malignant and benign human cancer cells, tissues and tumors through optimizing synchrotron microbeam radiotherapy for human cancer treatments and diagnostics: An experimental biospectroscopic comparative study. Glob Imaging Insights 3: 1-8.

202.A Heidari (2018) A hypertension approach to thermal infrared spectroscopy and photothermal infrared spectroscopy comparative study on malignant and benign human cancer cells and tissues under synchrotron radiation with the passage of time. Glob Imaging Insights 3: 1-8.

203.A Heidari (2018) Incredible Natural-Abundance Double-Quantum Transfer Experiment (INADEQUATE), Nuclear Overhauser Effect Spectroscopy (NOESY) and Rotating Frame Nuclear Overhauser Effect Spectroscopy (ROESY) Comparative study on malignant and benign human cancer cells and tissues under synchrotron radiation. Glob Imaging Insights 3: 1-8.

204.A Heidari (2018) 2-Amino-9-((1S, 3R, 4R)-4-Hydroxy-3-(Hydroxymethyl)-2-Methylenecyclopentyl)-1H-Purin-6(9H)-One, 2-Amino-9-((1R, 3R, 4R)4-Hydroxy-3-(Hydroxymethyl)-2-Methylenecyclopentyl)-1H-Purin-6(9H)-One, 2-Amino-9-((1R, 3R, 4S)-4-Hydroxy-3-(Hydroxymethyl)-2-Methylenecy- 
clopentyl)-1H-Purin-6(9H)-One and 2-Amino-9-((1S, 3R, 4S)-4-Hydroxy-3-(Hydroxymethyl)-2-Methylenecyclopentyl)-1H-Purin-6(9H)-One-enhanced precatalyst preparation stabilization and initiation nano molecules. Glob Imaging Insights 3: 1-9.

205.R Gobato, MRR Gobato, A Heidari, A Mitra (2018) Spectroscopy and dipole moment of the molecule $\mathrm{C} 13 \mathrm{H} 20 \mathrm{BeLi2SeSi}$ via quantum chemistry using $\mathrm{Ab}$ initio, Hartree-Fock method in the base set CCpVTZ and 6-311G**(3df, 3pd). American Journal of Quantum Chemistry and Molecular Spectroscopy 2: 9-17.

206. A Heidari (2018) Production of Electrochemiluminescence ( $\mathrm{ECL}$ ) Biosensor Using Os-Pd/HfC nanocomposites for detecting and tracking of human gastroenterological cancer cells, tissues and tumors. Int J Med Nano Res 5.

207.A Heidari (2018) Enhancing the raman scattering for diagnosis and treatment of human cancer cells, tissues and tumors using Cadmium Oxide (CdO) nanoparticles. J Toxicol Risk Assess 4.

208.A Heidari (2018) Human malignant and benign human cancer cells and tissues biospectroscopic analysis under synchrotron radiation using anticancer nano drugs delivery. Integr Mol Med 5: 1-13.

209.A Heidari (2018) Analogous nano compounds of the form $M\left(\mathrm{C}_{8} \mathrm{H}_{8}\right)_{2}$ Exist for $\mathrm{M}=(\mathrm{Nd}, \mathrm{Tb}, \mathrm{Pu}, \mathrm{Pa}$, $\mathrm{Np}$, Th, and $\mathrm{Yb}$ )-Enhanced Precatalyst Preparation Stabilization and Initiation (EPPSI) nano molecules. Integr Mol Med 5: 1-8.

210.A Heidari (2018) Hadron spectroscopy, baryon spectroscopy and meson spectroscopy comparative study on malignant and benign human cancer cells and tissues under synchrotron radiation. Integr Mol Med 5: 1-8.

211.R Gobato, MRR Gobato, A Heidari (2019) Raman spectroscopy study of the nano molecule $\mathrm{C}_{13} \mathrm{H}_{20} \mathrm{BeLi}_{2} \mathrm{SeSi}$ using $\mathrm{Ab}$ initio and Hartree-Fock Methods in the Basis Set CC-pVTZ and 6-311G** (3df, 3pd). International Journal of Advanced Engineering and Science 7: 14-35.

212.A Heidari, R Gobato (2019) Evaluating the effect of anti-cancer nano drugs dosage and reduced leukemia and polycythemia vera levels on trend of the human blood and bone marrow cancers under synchrotron radiation. Trends Res 2: 1-8.

213. A Heidari, R Gobato (2019) Assessing the variety of synchrotron, synchrocyclotron and LASER radiations and their roles and applications in human cancer cells, tissues and tumors diagnosis and treatment.
Trends in Res 2: 1-8.

214.A Heidari, R Gobato (2019) Pros and cons controversy on malignant human cancer cells, tissues and tumors transformation process to benign human cancer cells, tissues and tumors. Trends in Res 2: 1-8.

215.A Heidari, R Gobato (2019) Three-Dimensional (3D) simulations of human cancer cells, tissues and tumors for using in human cancer cells, tissues and tumors diagnosis and treatment as a powerful tool in human cancer cells, tissues and tumors research and anti-cancer nano drugs sensitivity and delivery area discovery and evaluation. Trends in Res 2: 1-8.

216.A Heidari, R Gobato (2019) Investigation of energy production by synchrotron, synchrocyclotron and LASER radiations in human cancer cells, tissues and tumors and evaluation of their effective on human cancer cells, tissues and tumors treatment trend. Trends in Res 2: 1-8.

217.A Heidari, R Gobato (2019) High-Resolution Mapping of DNA/RNA hypermethylation and hypomethylation process in human cancer cells, tissues and tumors under synchrotron radiation. Trends in Res 2: 1-9.

218. A Heidari (2019) A novel and comprehensive study on manufacturing and fabrication nanoparticles methods and techniques for processing Cadmium Oxide ( $\mathrm{CdO}$ ) nanoparticles colloidal solution. Glob Imaging Insights 4: 1-8.

219.A Heidari (2019) A combined experimental and computational study on the catalytic effect of Aluminum Nitride Nanocrystal (AIN) on the polymerization of benzene, naphthalene, anthracene, phenanthrene, chrysene and tetracene. Glob Imaging Insights 4: 1-8.

220.A Heidari (2019) Novel Experimental and ThreeDimensional (3D) multiphysics computational framework of michaelis-menten kinetics for catalyst processes innovation, characterization and carrier applications. Glob Imaging Insights 4: 1-8.

221.A Heidari (2019) The Hydrolysis Constants of Copper (I) $\left(\mathrm{Cu}^{+}\right)$and Copper (II) $\left(\mathrm{Cu}^{2+}\right)$ in aqueous solution as a function of $\mathrm{pH}$ using a combination of ph measurement and biospectroscopic methods and techniques. Glob Imaging Insights 4: 1-8.

222.A Heidari (2019) Vibrational biospectroscopic study of ginormous virus-sized macromolecule and polypeptide macromolecule as mega macromolecules using Attenuated Total Reflectance-Fourier Transform Infrared (ATR-FTIR) spectroscopy and mathe- 
matica 11.3. Glob Imaging Insights 4: 1-8.

223.A Heidari (2019) Three-Dimensional (3D) imaging spectroscopy of carcinoma, sarcoma, leukemia, lymphoma, multiple myeloma, melanoma, brain and spinal cord tumors, germ cell tumors, neuroendocrine tumors and carcinoid tumors under synchrotron radiation. Glob Imaging Insights 4: 1-9.

224.R Gobato, MRR Gobato, A Heidari, A Mitra (2019) New nano-molecule kurumi-C13H 20BeLi2SeSi/ C13H19BeLi2SeSi, and raman spectroscopy using ab initio, Hartree-Fock method in the base set CCpVTZ and 6-311G** (3df, 3pd). J Anal Pharm Res 8: 1-6.

225.A Heidari, J Esposito, A Caissutti (2019) The importance of Attenuated Total Reflectance Fourier Transform Infrared (ATR-FTIR) and raman biospectroscopy of Single-Walled Carbon Nanotubes (SWCNT) and Multi-Walled Carbon Nanotubes (MWCNT) in interpreting infrared and raman spectra of human cancer cells, tissues and tumors. Oncogen 2: 1-21.

226. A Heidari, J Esposito, A Caissutti (2019) Study of anti-cancer properties of thin layers of Cadmium Oxide (CdO) nanostructure. Int J Analyt Bioanalyt Methods.

227.R Gobato, MRR Gobato, A Heidari (2019) Evidence of tornado storm hit the counties of Rio Branco do Ivaí and Rosario de Ivai, Southern Brazil. Sci Lett 7.

228.A Heidari, J Esposito, A Caissutti (2019) The quantum entanglement dynamics induced by nonlinear interaction between a moving nano molecule and a two-mode field with two-photon transitions using reduced von neumann entropy and jaynescummings model for human cancer cells, tissues and tumors diagnosis. Int J Crit Care Emerg Med 5: 071-084.

229.A Heidari (2019) Mechanism of action and their side effects at a glance prevention, treatment and management of immune system and human cancer nano chemotherapy. Nanosci Technol 6: 1-4.

230.A Heidari, J Esposito, A Caissutti (2019) The Importance of Quantum Hydrodynamics (QHD) approach to Single-Walled Carbon Nanotubes (SWCNT) and Multi-Walled Carbon Nanotubes (MWCNT) in genetic science. SCIOL Genet Sci 2: 113-129.

231.A Heidari, J Esposito, A Caissutti (2019) Palytoxin time-resolved absorption and resonance FT-IR and raman biospectroscopy and Density Functional Theory (DFT) investigation of vibronic-mode coupling structure in vibrational spectra analysis. J Pharm Drug Res 3: 150-170.

232.A Heidari, J Esposito, A Caissutti (2019) Aplysiatoxin time-resolved absorption and resonance FT-IR and raman biospectroscopy and Density Functional Theory (DFT) investigation of vibronic-mode coupling structure in vibrational spectra analysis. J J Chem Sci Eng 2: 70-89.

233.A Heidari, J Esposito, A Caissutti (2019) Cyanotoxin time-resolved absorption and resonance FT-IR and raman biospectroscopy and Density Functional Theory (DFT) investigation of vibronic-mode coupling structure in vibrational spectra analysis. British Journal of Medical and Health Research 6: 1-41.

234.A Heidari (2019) Potential and theranostics applications of novel anti-cancer nano drugs delivery systems in preparing for clinical trials of Synchrotron Microbeam Radiation Therapy (SMRT) and Synchrotron Stereotactic Radiotherapy (SSRT) for treatment of human cancer cells, tissues and tumors using Image Guided Synchrotron Radiotherapy (IGSR). Ann Nanosci Nanotechnol 3: 1006-1019.

235.A Heidari (2019) Clinical and medical pros and cons of human cancer cells' enzymotherapy, immunotherapy, chemotherapy, radiotherapy, hormone therapy and targeted therapy process under synchrotron radiation: A case study on mechanism of action and their side effects. Parana Journal of Science and Education 5: 1-23.

236.A Heidari (2019) The importance of the power in CMOS inverter circuit of synchrotron and synchrocyclotron radiations using $50(\mathrm{~nm})$ and $100(\mathrm{~nm})$ technologies and reducing the voltage of power supply. Radiother Oncol Int 1: 1002-1015.

237.A Heidari, J Esposito, A Caissutti (2019) Anatoxin-a and Anatoxin-a(s) time-resolved absorption and resonance FT-IR and raman biospectroscopy and Density Functional Theory (DFT) investigation of vibronic-mode coupling structure in vibrational spectra analysis. Saudi J Biomed Res 4: 174-194.

238. A Heidari, J Esposito, A Caissutti (2019) AlphaConotoxin, Omega-Conotoxin and Mu-Conotoxin Time-resolved absorption and resonance FT-IR and raman biospectroscopy and Density Functional Theory (DFT) investigation of vibronic-mode coupling structure in vibrational spectra analysis. International Journal of Advanced Chemistry 7: 5266. 